\title{
Globalization and the dynamics of cultural identity
}

\author{
Jacques Olivier ${ }^{\mathrm{a}, \mathrm{b}}$, Mathias Thoenig ${ }^{\mathrm{b}, \mathrm{c}, \mathrm{d}, *}$, Thierry Verdier ${ }^{\mathrm{b}, \mathrm{d}}$ \\ a HEC Paris, France \\ b CEPR, United Kingdom \\ c Université de Genève, Switzerland \\ d Paris School of Economics, France
}

\section{A R T I C L E I N F O}

\section{Article history:}

Received 15 March 2006

Received in revised form 1 May 2007

Accepted 23 June 2008

\section{Keywords:}

Cultural identity

Cultural transmission

International trade

JEL classification:

F02

F10

Z10

$\mathrm{Z} 13$

\begin{abstract}
A B S T R A C T
This paper presents a simple model where micro-founded dynamics of cultural identity are endogenous and interact with an international trade equilibrium. This process generates a strong home bias under autarky. We then show that goods market integration causes a phenomenon of cultural divergence, whereby the distributions of cultures become more dissimilar across countries and one of the cultures that existed under autarky ultimately disappears. By way of contrast, we show that social integration causes cultural convergence and can counterbalance the effects of goods market integration.
\end{abstract}

(C) 2008 Elsevier B.V. All rights reserved.

\section{Introduction}

Revolutionary developments in information and transport technology are changing the world. Our daily lives are governed by products and images originating from other countries and other cultures. Common wisdom among economists is that the benefits from international integration and globalization are clear and significant. International trade should bring efficiency gains in production and access to an increased variety of goods and services. This approach is however at odds with the concerns of other social scientists over globalization and the strong defensive attitudes of anti-globalization movements and NGOs. Indeed, one of the strongest critics to globalization comes from the fear that such a process might erode national cultures and individual identities. ${ }^{1}$

\footnotetext{
* Corresponding author.

E-mail address: thoenig@ecopo.unige.ch (M. Thoenig).

1 Some striking anecdotal evidence comes from France. 60\% of respondents in a 1999 L'Expansion magazine poll agreed that globalization represented the greatest threat to the French way of life (Meunier 2000). 19\% of respondents in a 2005 TF1 poll said that they voted against the European constitution because "Europe threatens the French cultural identity". Beyond evidence from case studies, this fear of cultural erosion appears in formal empirical studies. Mayda and Rodrik (2005) have used a unique data set put together by the International Social Survey Programme covering over 20,000 individuals in 23 countries, which provides not only the usual socioeconomic and demographic variables but also responses to questions aimed at eliciting both the individuals' set of "values" and their attitude toward trade. Mayda and Rodrick find that a number of non-economic variables consistently appear as significant in their regressions, in a way that traditional workhorse models in international trade cannot predict. In particular, they report that "Non-economic determinants, in the forms of values, identities and attachments play an important role in explaining the variations of preferences over trade. High degrees of neighborhood attachment and nationalism/ patriotism are associated with protectionist attitudes".
} 
While there has been much discussion in the public debate on the interdependence of globalization and culture and while cultural aspects seem to explain a significant part of the resistance of the general public to trade integration, so far little economic analysis has formally discussed these issues. The purpose of this paper is to provide a formal economic analysis of the link between openness and cultural evolution. Our main objective is to provide a simple benchmark where the dynamics of culture is endogenous and interacts with a simple international trade equilibrium. Our approach is positive and not normative. As we know, normative analyses with endogenous preferences are always difficult. We briefly touch normative issues at the very end of the paper but otherwise limit ourselves to positive statements, hoping simply that our framework will provide useful steps for discussions in normative terms in future research.

Following the view developed recently by Akerlof and Kranton (2000), we model cultural identity as a positive group externality among agents who share the same culture and who adopt similar consumption patterns for a particular type of good, a "cultural good". In addition to its intrinsic economic value, consumption of a cultural good confers symbolic and non-pecuniary value. It reinforces a sense of belonging to a particular community of people and facilitates social exchange within that community.

In our model, different cultures coexist in any given country and the fraction of individuals belonging to each culture is endogenous. Cultural identity comes as the outcome of a dynamic process of transmission of preferences as micro-founded for instance by Bisin and Verdier (2000) and Francois (2002). Parents are altruistic with respect to their offsprings but value the consumption of their child only through the filter of their own preferences. A child who has preferences different from her parents chooses a consumption bundle that maximizes her own utility but is sub-optimal from her parents' perspective. Parents thus have incentives to spend resources to transmit their preferences to their children. Depending on the relative socialization efforts of parents of different cultures, the distribution of individuals among the communities evolves and reaches a long-run stationary state.

Using this approach, our analysis highlights the existence of two-sided interactions between cultural dynamics and market economic equilibrium. Cultural identity impacts on prices and the allocation of resources through traditional demand driven effects. The larger the size of a given cultural community, the larger the demand for its attached cultural good and the higher its equilibrium price.

Reciprocally, the nature of the economic equilibrium feedbacks on cultural dynamics through two mechanisms. First, a relative price effect tends to promote cultural heterogeneity within the society. Indeed, the larger a given cultural community, the larger the equilibrium price of the cultural good attached to that community, the lower the cost for a parent to see her child not consuming that good and thus the lower the incentives for parents of that community to transmit their own cultural traits. Secondly, a cultural externality effect tends to promote homogenization within the society: the larger a given cultural community, the larger the cultural externality and therefore the larger the cost for a parent of that community to imagine her offspring different from her and not enjoying the externality.

Consequently, preferences are endogenous in the long run and depend on supply side characteristics of the economy such as factor endowments and technology. This is a source of non-Walrasian effects such that an increase in the relative abundance of a specific production factor may in fact increase and not decrease the long-run equilibrium price of the good using intensively that factor. From an international trade perspective, it means that the cause of trade between two countries may rely directly and indirectly on differences in factor endowments, directly through the traditional supply side channels, indirectly through the way endowments affect the evolution of preferences. We show that this feature provides a rationale for the existence of a home bias in preferences, a fact extensively discussed in the empirical literature.

Our main results are related to the impact of goods market integration on the distribution of cultures. We show that goods market integration causes cultural divergence: the distribution of cultures becomes more dissimilar across countries over time after countries have opened to trade. We further show that in the long-run, one of the cultures that existed under autarky must disappear in each country. As a consequence, openness may generate tensions within the society along lines consistent with the evidence put forward by Mayda and Rodrik (2005).

We then consider the impact of social integration. We say that two countries are socially integrated when social exchanges with agents of one's own country are as frequent as social exchanges with agents of the other country. We show that contrary to goods market integration, social integration causes cultural convergence, in the sense that the distribution of cultures becomes more similar across countries over time. We then provide an example where the effects of social integration and goods market integration perfectly cancel one another and where complete integration has no impact on culture.

This paper is related to the small but rapidly expanding literature addressing the impact of culture on trade. On the empirical side, Guiso et al. (2005) provide strong evidence that cultural biases help explain the extent of bilateral trade and foreign direct investment across countries. ${ }^{2}$ On the theory side, two closely related papers to ours are Janeba (2004) and Rauch and Trindade (2006), who also model cultural identity as a consumption externality. Janeba (2004) studies the impact of cultural identity on the nature of the economic equilibrium under free trade. He highlights non-trivial effects of trade openness on welfare for a given and exogenous population of cultural agents. Rauch and Trindade (2006) extend Janeba's set-up and allow for imperfect competition and innovation in the cultural sector. ${ }^{3}$ Our purpose here is complementary to this literature as our focus is on the reverse causal link, namely the impact of trade openness on (endogenous) cultural identity.

\footnotetext{
2 See also Gould (1994) and Head and Ries (1998) for evidence that immigration plays an important role in increasing trade flows with the immigrants' home country, which is consistent with the hypothesis that consumption patterns are driven by culture. Disdier et al. (2006) study the impact of foreign media on name patterns and look at their time evolution across French regions.

${ }^{3}$ See also Francois and Van Ypersele (2001) and Ramezzana (2003), who study the optimal degree of trade protection in presence of heterogenous preferences over differentiated goods in a context of non-competitive or monopolistic markets.
} 
A dynamic analysis of culture is also presented in Bala and Van Long (2005). But their view of culture is different as they look at individual preferences on rival goods rather than cultural identity as a group externality. More importantly, their cultural dynamics are driven by an exogenous process directly imported from the Darwinian literature in biology, while cultural transmission in our model is founded on a socialization mechanism explicitly grounded on microfoundations. ${ }^{4}$

The remainder of the paper is organized as follows. Section 2 presents the basic model; in Section 3 we solve for the equilibrium dynamics of cultural identity under autarky. Section 4 is devoted to the analysis of trade integration and Section 5 to social integration. Finally Section 6 concludes and discusses potential extensions.

\section{The model}

Our objective is to provide a simple framework where culture affects trade and trade affects culture. With this goal in mind, we propose a model with three ingredients. The first ingredient is the production side of a highly simplified factor endowment model. The second ingredient is agent's preferences that allow for "cultural externalities". In this respect, we follow Akerlof and Kranton (2000) and posit that agents who share a common cultural identity benefit from a positive group externality when they engage in actions deemed appropriate by their culture. The last ingredient of our model deals with the dynamics of cultures and follows the lines of micro-founded models of imperfect altruism. ${ }^{5}$

We now present each ingredient of the model separately: first, the production structure, then preferences, and last the dynamics.

\subsection{Production structure}

We consider an economy with two countries and two (cultural) goods $X_{i}$ indexed by a subscript $i=1,2$. Each good $X_{i}$ is produced with labor $L$ and with a specific factor, which we call a cultural capital $K_{i}$. Factors of production are immobile and in fixed supply in each country. Ownership of factors is shared equally among agents. Production functions are given by:

$$
\begin{gathered}
X_{i}=\widehat{\beta} L^{1-\beta}\left(K_{i}\right)^{\beta} \\
\text { with } \beta \in(0,1) \\
\text { and } \widehat{\beta}=\beta^{-\beta}(1-\beta)^{-(1-\beta)} .
\end{gathered}
$$

The way we think of the cultural capital $K_{i}$ is mostly in terms of country specific factor, mixing geographical, climatic, historical and human capital features. If we think of cuisine in famous restaurants as an example of a cultural good, $K_{i}$ could be thought of as the combination of the chef's talent and country culinary customs. Our assumptions about production imply that the human capital of chefs is specific to the production of high cuisine and that the limited supply of talented chefs in the economy is the source of decreasing returns. If we think of wine as another (complementary) cultural good, the fixed supply of the appropriate soil/climate combination is again the source of decreasing returns.

The main feature of the neoclassical production structure above is that when the relative demand for a good $K_{i}$ increases, the relative price of that good increases as well. A legitimate concern is that this feature may not be appropriate for some cultural industries (e.g. the movie industry), where increasing returns prevail, at least at the distribution stage. As can be expected, introducing increasing returns would push the economy toward corner solutions. We show in Section 4 that trade integration has extreme impacts on the distribution of cultures despite the stabilizing force provided by decreasing returns. In that sense, we view decreasing returns as a conservative assumption to tie our hands.

\subsection{Preferences and the cultural externality}

We associate cultural identity with agents' preferences: two agents have the same preferences if and only if they have the same culture. A simplifying assumption is that the consumption of the two cultural goods is mutually exclusive: if an agent chooses to consume good $X_{i}$, she cannot consume good $X_{j \neq i}$. We note by $q_{i, t}$ the fraction of agents belonging to culture $i$ at date $t$.

Agents derive utility from individual consumption and, possibly, from social exchange with other agents in the same country. If a social exchange does not occur, the utility of each agent is linear: agents get utility equal to the quantity of the good they consumed.

The rules for social exchange are as follows. Each period, a matching process takes place within each country. Matching is random. Thus, with probability $q_{i, t}$ an agent is matched with an agent of culture $i$. A social exchange is possible only if the two agents matched together share the same cultural identity. If this is the case, the utility of each agent who has consumed their common cultural good is multiplied by a social exchange coefficient $\mathrm{SE}_{i}$ larger than 1 . Otherwise, utility is left unchanged by the match.

\footnotetext{
${ }^{4}$ See Bisin and Verdier (2001) for a comparison of evolutionary selection and cultural transmission mechanisms.

5 This approach builds and extends the cultural anthropology and population dynamics literature (Cavalli-Sforza and Feldman, 1981; Boyd and Richerson, 1985).
} 
Given this specification, an agent of culture $i$ who consumes a cultural good $X_{j \neq i}$ different from her own cultural good cannot benefit from social exchange and thus gets a utility level given by:

$$
U_{i}\left(x_{j \neq i, t}\right)=x_{j, t} .
$$

While the expected utility of an agent of culture $i$ who consumes her cultural good $X_{i}$ is given by:

$$
U_{i}\left(x_{i, t}\right)=\left(1-q_{i, t}\right) x_{i, t}+\mathrm{SE}_{i} q_{i, t} x_{i, t} .
$$

This expression can be simplified by defining:

$$
I_{i}\left(q_{i, t}\right) \equiv\left(1+q_{i, t}\left(\mathrm{SE}_{i}-1\right)\right) .
$$

Which yields:

$$
U_{i}\left(x_{i, t}\right)=\left(I_{i}\left(q_{i, t}\right)\right) x_{i, t} .
$$

Comparing Eqs. (5) and (2), one can interpret $I_{i}\left(q_{i, t}\right)$ as the cultural externality associated at date $t$ with the consumption of the good $X_{i}$. Note that the function $I_{i}\left(q_{i, t}\right)$ is increasing, bounded below by 1 and takes value 1 either if the mass of agents of culture $i$ falls to 0 or if $\mathrm{SE}_{i}=1$.

\subsection{Dynamics of preferences}

At this stage, we have described production and preferences at a given date $t$. We now endogenize how preferences evolve through time.

Demographics in our model follow a simple overlapping generation structure: between $t$ and $t+\mathrm{d} t$, a fraction $\lambda \mathrm{d} t$ of individuals retire. Just before retiring, these individuals (parents) give birth to offsprings. Parents may spend resources to transmit their preferences to their offsprings. The more resources are spent by the parents, the higher is the probability that the preferences of the offspring are the same as the preferences of her parents. If parents are not successful in transmitting their own preferences, then the offspring adopts the preferences of some other agent of the economy she has been randomly matched with. ${ }^{6}$ Thus the dynamics of $q_{i, t}$ are driven by the relative resources spent by parents of different cultures in order to transmit their preferences to their offspring.

The key assumption to determine the amount of resources spent by each parent to socialize her offspring is that parents are imperfectly altruistic. Parents derive utility from their children's consumption but value their children' consumption through the filter of their own preferences. This implies that if their offspring ends up with preferences different from their own, she chooses a consumption profile that maximizes her own utility but not her parents' utility. Thus, it is optimal for a rational parent to spend valuable resources to raise the probability of her child adopting her parents' preferences.

Following Bisin and Verdier (2000), we define $V_{i j, t}$ the expected utility of an agent whose preferences are of type $i$ and whose consumption choice is the optimal consumption behavior of an agent of type $j$ at date $t$. Obviously, $V_{i i, t}$ simply represents the maximum level of utility achievable at date $t$ by an agent of type $i$. When offsprings are of a different cultural type $j$, it is costly for altruistic parents of type $i$ to see their kids make consumption choices that are sub-optimal from their point of view. We note this cost, which we call a subjective utility cost, $\Delta V_{i, t} \equiv V_{i i, t}-V_{i j, t}$.

We define the parents' optimization problem, solve the problem and derive explicit dynamics of $q_{i, t}$ in the Appendix. The exact functional form of these dynamics will not play an important role in the rest of the paper. However, the following properties are crucial:

$$
\begin{aligned}
& \dot{q}_{i, t}>0 \text { iff } \Delta V_{i, t}>\Delta V_{j, t} \text { and } q_{i, t} \in(0,1) \\
& \dot{q}_{i, t}=0 \text { iff } \Delta V_{i, t}=\Delta V_{j, t} \text { or } q_{i, t} \in\{0,1\} .
\end{aligned}
$$

The dynamics of $q_{i, t}$ are easy to interpret: the larger is the subjective utility cost for parents of a given culture of having their offspring adopt different preferences, the more resources will be spent by parents of that culture to socialize their children and the more prevalent this culture will become over time. A steady-state is reached if subjective utility costs, and thus socialization efforts, are equalized across parents of different cultures.

\footnotetext{
${ }^{6}$ This specification captures the idea that children acquire preferences through observation and imitation. This happens at two levels: $a$ ) inside the family (vertical cultural transmission); b) on the outside cultural and social environment via teachers, peers, etc. (oblique cultural transmission). An alternative specification that yields similar dynamics relies on socialization by peers (horizontal cultural transmission). For the sake of brevity, the alternative specification is not included in this version of the paper but is available upon request.
} 


\section{Autarkic equilibrium}

We first solve for a short-run equilibrium, that is the equilibrium of the economy for given $q_{i, t}$. We then solve for the equilibrium dynamics of $q_{i, t}$. We finally show that the long-run equilibrium exhibits a home bias property.

\subsection{Short-run equilibrium}

From the utility functions (2) and (5), it is straightforward to show that an agent of culture $i$ strictly prefers to consume good $X_{i}$ if and only if $p_{i, t}<I_{i}\left(q_{i, t}\right) p_{j, t}$. This in turn implies that three different equilibrium regimes can exist, depending on the value of the only state variable of this economy $q_{1, t}$ a pooling regime, where $p_{1, t}=I_{1}\left(q_{1, t}\right) p_{2, t}$ and agents of culture 1 are indifferent between consuming goods $X_{1}$ and $X_{2}$ while agents of culture 2 strictly prefer $X_{2}$ to $X_{1}$; a second pooling regime, where $p_{2, t}=I_{2}\left(1-q_{1, t}\right) p_{1, t}$ and agents of culture 2 are indifferent between the two goods while agents of culture 1 strictly prefer $X_{1}$; and an interior regime where $\frac{1}{I_{2}\left(1-q_{1, t}\right)}<\frac{p_{1, t}}{p_{2}, t}<I_{1}\left(q_{1, t}\right)$ and where each agent strictly prefers to consume her own cultural good. We show in Section 3.2 that the two pooling regimes are incompatible with the long-run dynamics of $q_{1, t}$. We thus focus on the interior regime where both goods are produced and consumed.

With obvious notation, we have under perfect competition:

$$
\left\{\begin{array}{l}
p_{1, t}=w_{t}^{1-\beta} r_{1, t}^{\beta} \\
p_{2, t}=w_{t}^{1-\beta} r_{2, t}^{\beta}
\end{array}\right.
$$

Without loss of generality, we normalize total expenditure to 1 . In the interior regime, we get the following aggregate demands:

$$
\left\{\begin{array}{l}
q_{1, t}=w_{t}^{1-\beta} r_{1, t}^{\beta} x_{1, t} \\
\left(1-q_{1, t}\right)=w_{t}^{1-\beta} r_{2, t}^{\beta} x_{2, t}
\end{array} .\right.
$$

From market clearing, competition in the factor markets and Eq. (9), we get:

$$
\left\{\begin{array}{l}
w_{t}=\frac{(1-\beta)}{L} \\
r_{1, t}=\frac{\beta q_{1, t}}{K_{1}} \\
r_{2, t}=\frac{\beta\left(1-q_{1, t}\right)}{K_{2}}
\end{array}\right.
$$

Finally, we obtain from Eqs. (8) and (10) one of the two key equations of our model, which provides relative prices as a function of the relative masses of agents of each culture in the economy:

$$
\frac{p_{1, t}}{p_{2, t}}=\left(\frac{r_{1, t}}{r_{2, t}}\right)^{\beta}=\left(\frac{K_{2}}{K_{1}}\right)^{\beta}\left(\frac{q_{1, t}}{1-q_{1, t}}\right)^{\beta} .
$$

Eq. (11) represents a short-run equilibrium condition, that is where $q_{1, t}$ is taken as given. It can easily be verified that the relative price of a cultural good is an increasing function of the mass of agents of the corresponding culture.

\subsection{Cultural dynamics}

We now solve for the dynamics of $q_{1, t}$. The first step is to derive the subjective utility costs for parents of both types, $\Delta V_{1, t}$ and $\Delta V_{2, t}$, as defined in Section 2.3, as a function of $q_{i, t}$. Cases easy to deal with are the two pooling regimes:

By construction, the first pooling regime is such that agents of culture 1 are indifferent between consuming goods $X_{1}$ and $X_{2}$ which implies that $\Delta V_{1, t}=0$, and such that agents of culture 2 strictly prefer $X_{2}$ to $X_{1}$, which implies $\Delta V_{2, t}>0$. Similarly, the second pooling regime is such that $\Delta V_{2, t}=0$ and $\Delta V_{1, t}>0$.

We next derive the subjective utility costs in the interior regime. From Eqs. (5) and (10), we get:

$$
V_{i i, t}=\frac{I_{i}\left(q_{i, t}\right)}{p_{i, t}}
$$

While we get from Eqs. (2) and (10):

$$
V_{i j, t}=\frac{1}{p_{j, t}} .
$$

Which yields:

$$
\Delta V_{i, t}=\left(\frac{I_{i}\left(q_{i, t}\right)}{p_{i, t}}\right)-\left(\frac{1}{p_{j, t}}\right)
$$


We then obtain the following ratio between the subjective utility costs of parents of each culture:

$$
\frac{\Delta V_{1, t}}{\Delta V_{2, t}}=\frac{\left(I_{1}\left(q_{1, t}\right)\right) p_{2, t}-p_{1, t}}{\left(I_{2}\left(1-q_{1, t}\right)\right) p_{1, t}-p_{2, t}} .
$$

We are now equipped to derive the dynamics of $q_{i, t}$. For the ease of exposition we focus in the rest of this paper on the case where cultural externalities $\left(\mathrm{SE}_{1}, \mathrm{SE}_{2}\right)$ are not too large and verify:

$$
\left\{\begin{array}{l}
\forall i, \mathrm{SE}_{i}<1+\frac{4 \beta}{(1-\beta)^{2}} \\
2\left(\mathrm{SE}_{1}-1\right)+2\left(\mathrm{SE}_{2}-1\right)+\left(\mathrm{SE}_{1}-1\right)\left(\mathrm{SE}_{2}-1\right)<16 \beta
\end{array} .\right.
$$

These conditions yield very reasonable values. Indeed considering that $\beta$, the coefficient of capital in the CobbEq. (1)) is equal to $1 / 3$, the two conditions impose that $\mathrm{SE}_{i}<2$. This means that cultural externalities can amplify at most by two times agents' utility when they consume the cultural goods. This, we believe, is already a large number and should encompass most of real world situations.

We show now that there exists a unique steady-state. In the Appendix, we establish that there necessarily exists $0<q<\bar{q}<1$ such that the first pooling regime prevails for $q_{1, t} \in[\bar{q}, 1]$ and the second pooling regime prevails for $q_{1, t} \in[0, q]$. From the discussion of the pooling regimes above and from Eq. (6), we know that $\dot{q}_{1, t}<0$ in the first pooling regime and that $\dot{q}_{1, t}>0$ in the second pooling regime. Thus, if a steady-state exists, it must necessarily be in the interior regime where $q_{1, t} \in(\underline{q}, \bar{q})$.

From Eq. (6) and from Eq. (13), we know that in the interior regime:

$$
\dot{q}_{1, t} \geq 0 \Leftrightarrow \frac{1+I_{1}\left(q_{1, t}\right)}{1+I_{2}\left(1-q_{1, t}\right)} \geq \frac{p_{1, t}}{p_{2, t}}
$$

Or, by substituting Eq. (11):

$$
\dot{q}_{1, t} \geq 0 \Leftrightarrow \frac{1+I_{1}\left(q_{1, t}\right)}{1+I_{2}\left(1-q_{1, t}\right)} \geq\left(\frac{K_{2}}{K_{1}}\right)^{\beta}\left(\frac{q_{1, t}}{1-q_{1, t}}\right)^{\beta} .
$$

Eq. (15) shows how the dynamics of cultures result from two effects going in opposite directions. The first effect, captured in the LHS of Eq. (15), is a cultural externality effect: the larger the size of a given culture, the larger the cultural externality and the more

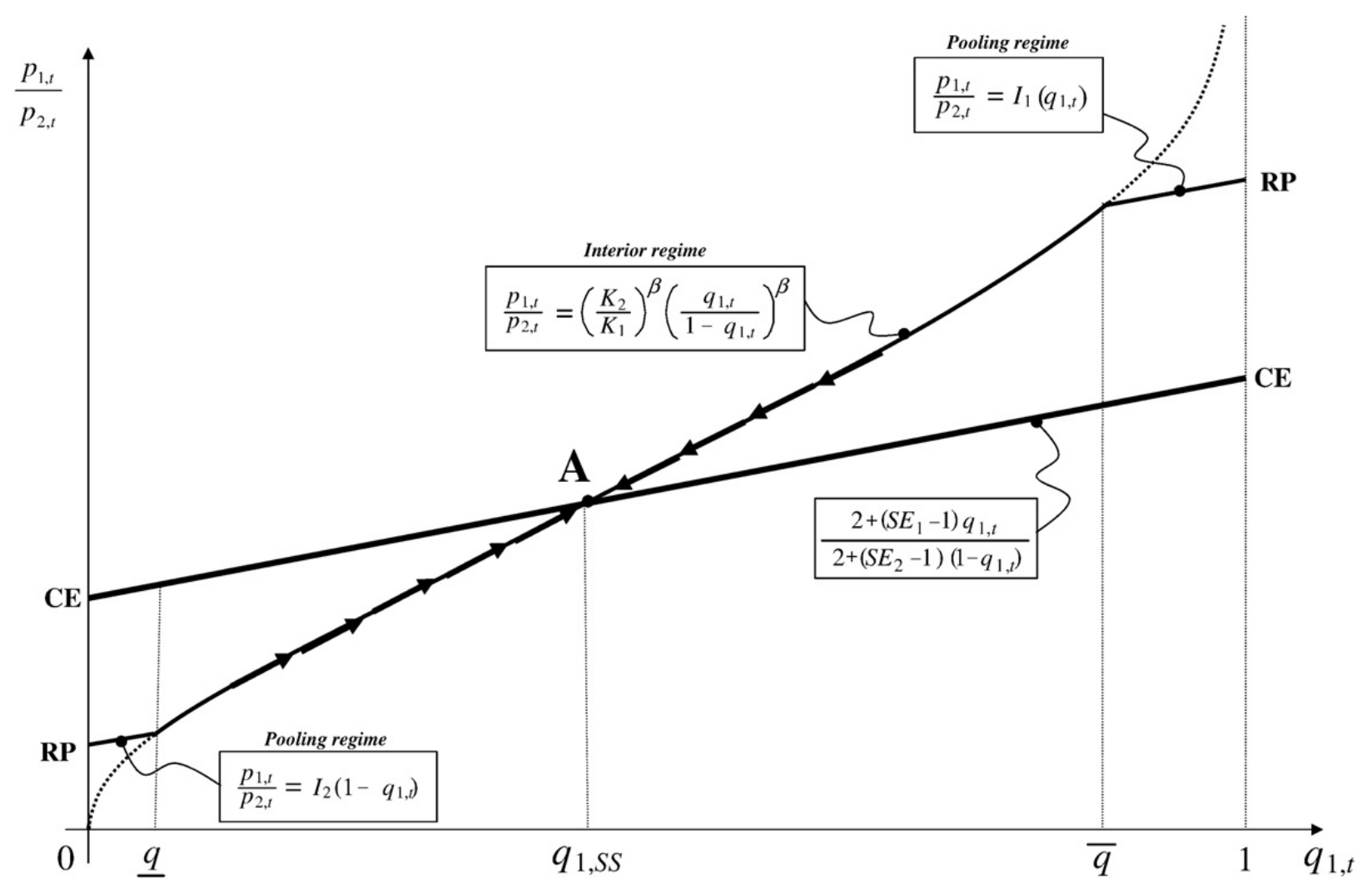

Fig. 1. Phase diagram (Autarky). 
parents of that culture have incentives to socialize their children. The second effect, captured in the RHS of Eq. (15), is a relative price effect: the larger the size of a given culture, the larger the demand for the corresponding cultural good, the larger the relative price of that good and the less parents of that culture have incentives to socialize their children. The relative price effect tends to promote cultural heterogeneity within the society while the cultural externality effect tends to promote homogeneity.

A steady-state is reached when the two effects exactly compensate one another:

$$
\frac{p_{1, \mathrm{SS}}}{p_{2, \mathrm{SS}}}=\frac{1+I_{1}\left(q_{1, \mathrm{SS}}\right)}{1+I_{2}\left(1-q_{1, \mathrm{SS}}\right)}=\left(\frac{K_{2}}{K_{1}}\right)^{\beta}\left(\frac{q_{1, \mathrm{SS}}}{1-q_{1, \mathrm{SS}}}\right)^{\beta}
$$

In the Appendix we show that there exists a unique solution to Eq. (16), which corresponds to a unique stable interior steadystate.

Even though Eq. (16) does not admit an explicit analytical solution, we can rely on a graphical analysis. Fig. 1 represents the two key equations of our model and the resulting one dimensional phase diagram: Eq. (11) is the short-run equilibrium condition, which states that the larger is the mass of agents of a given culture, the higher should be the price of the corresponding cultural good. It is represented by the upward sloping curve RP (as in Relative Price). From Eq. (14), we know that relative prices must equate the ratio of the cultural externalities at the steady-state. This condition is represented by the upward sloping curve $\mathrm{CE}$ (as in Cultural Externality). From Eq. (16), we know that a long-run equilibrium is found at the intersection of RP and CE, which is on point A on the graph. Note that Eq. (14) implies that if $\frac{p_{1, t}}{p_{2, t}}$ is below CE then $\dot{q}_{1, t}>0$. Stability of the steady-state implies that RP intersects CE from below, as represented in Fig. 1.

\subsection{Long-run equilibrium and the home bias}

We now discuss some properties of the long-run equilibrium. In Fig. 2 we perform a simple comparative static. Suppose the economy has reached its long-run equilibrium $A$ and that it is hit by a shock that decreases its stock of cultural capital $K_{1}$. From Eq. (11), we know that a lower $K_{1}$ implies that the RP curve shifts up, to curve RP'. If preferences were not endogenous, that is if $q_{i, t}$ were constant, this would imply a higher relative price for good $X_{1}$, as indicated by point B on the graph. However, in our model with endogenous preferences the economy does not remain at point B. Since point B lies above the CE curve, $\dot{q}_{1, t}<0$. This is because at point $\mathrm{B}$, good $X_{1}$ is too expensive compared to the cultural externalities it provides, which strengthens the incentives of parents of culture 2 and weakens the incentives of parents of culture 1 to socialize their offsprings. Thus, the economy gradually moves downward along the $\mathrm{RP}^{\prime}$ curve. As $q_{1, t}$ decreases, cultural externalities of good $X_{1}$ are further reduced, which amplifies the initial effect and pushes the price of good $X_{1}$ further down. Finally, a new long-run equilibrium is reached at point $\mathrm{C}$, where the RP' curve intersects the CE curve.

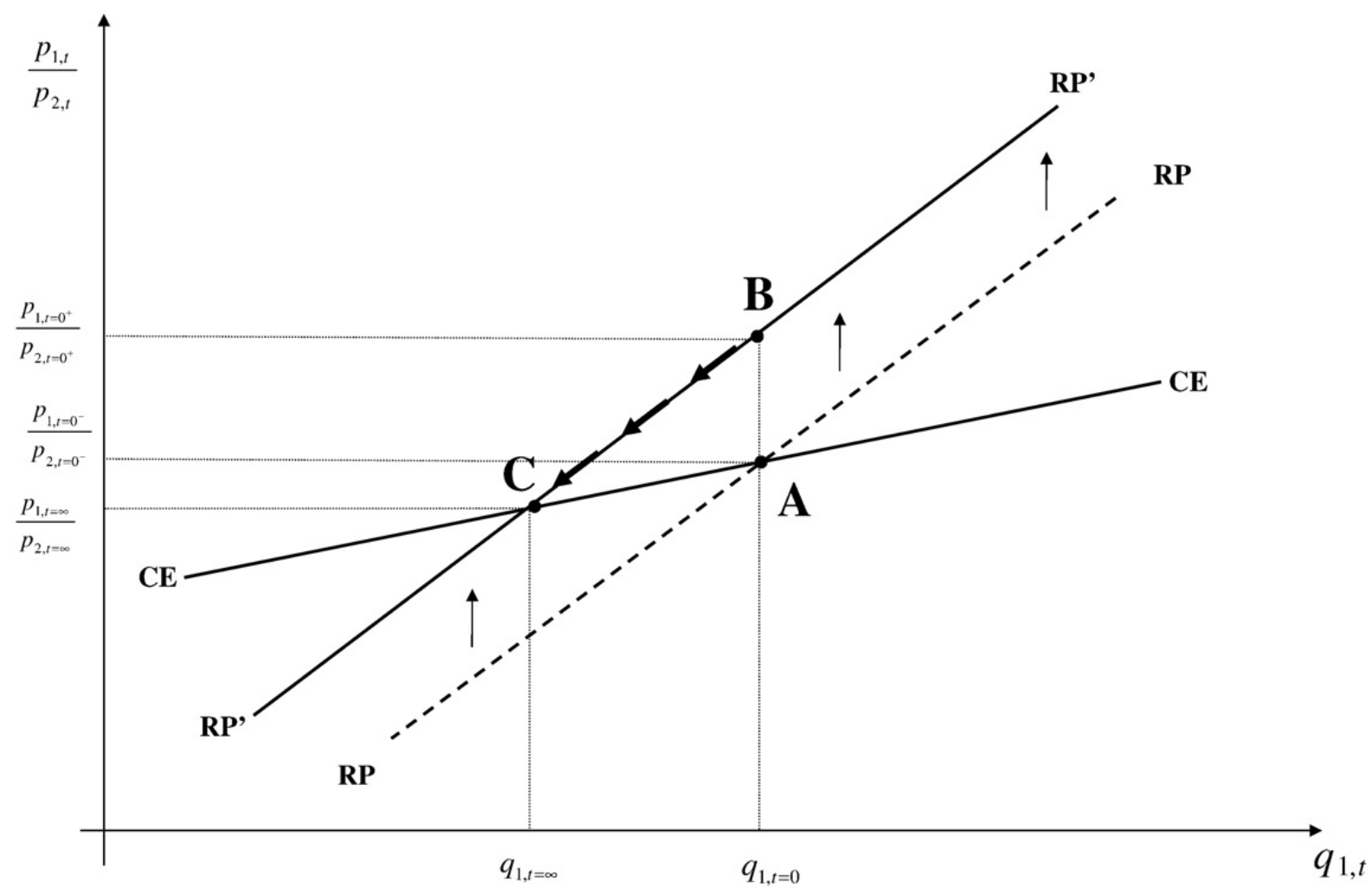

Fig. 2. Comparative static in $\mathrm{K}$. 


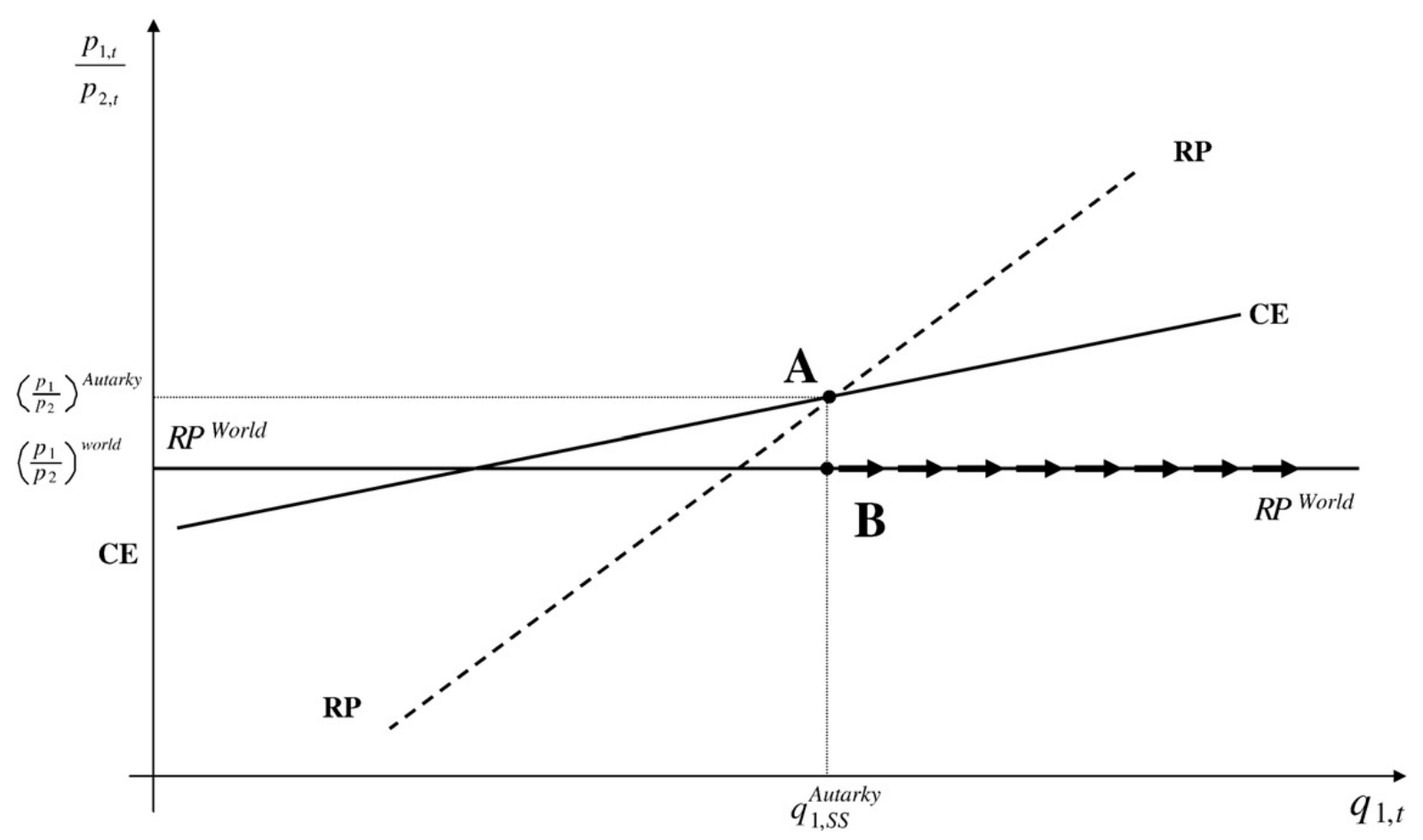

Fig. 3. Trade integration for small open economy.

The important feature of the new long-run equilibrium is that the relative price of good $X_{1}$ is not only lower than its value in the short-run equilibrium B but also strictly lower than at the previous long-run equilibrium, $A$. In other words, we observe a strong home bias: the equilibrium price of a cultural good is increasing in the relative abundance of factors specific to its production. Indeed, domestic preferences are (endogenously) biased towards goods produced in relative abundance in the economy. Furthermore the effect is strong enough to overcome the standard factor endowment effect because of the presence of cultural externalities. ${ }^{7}$

\section{Trade integration}

We now discuss the impact of the integration of goods markets on the dynamics of cultural identities.

\subsection{Trade integration in a small open economy}

The simplest setting in which one can discuss the impact of trade integration on local cultures is that of a small open economy. We represent in Fig. 3 a scenario where the two cultural goods $X_{1}$ and $X_{2}$ are traded and where the local economy has a comparative advantage in good $X_{2}$, or: $\left(\frac{p_{1}}{p_{2}}\right)^{\text {Autarky }}>\left(\frac{p_{1}}{p_{2}}\right)^{\text {world }}$. When a small economy opens to trade, prices shift to world prices, as local demand is too small to affect world prices. This implies that the new short-run equilibrium curve, $R P^{\text {world }}$, is horizontal. Furthermore, since $\left(\frac{p_{1}}{p_{2}}\right)^{\text {Autarky }}>\left(\frac{p_{1}}{p_{2}}\right)^{\text {world }}$, the curve RP $P^{\text {world }}$ is located below point A around $q_{1, S S}^{\text {autarky }}$. The economy moves to point B in the short-run. At point B however, good $X_{1}$ is cheaper compared to the cultural externalities it provides, which implies that $\dot{q}_{1, t}>0$. As $q_{1, t}$ increases, cultural externalities of good $X_{1}$ are strengthened, which amplifies the initial effect of trade integration. Unlike the autarky scenario discussed earlier, and given the small open economy assumption, the change in local demand does not translate into a change of the relative price. Hence, there is no force preventing $q_{1, t}$ from increasing further and the economy converges to a long-run equilibrium where $q_{1, t}=1$.

Note that our previous discussion of the home bias implies that the small economy has a comparative advantage in good $X_{2}$ if and only if it starts with a larger fraction of agents of culture 1 under autarky than the fraction of agents of culture 1 in the rest of the world. Thus opening to trade exacerbates the differences that exist under autarky in terms of distribution of cultures between the small economy and the rest of the world. We call this phenomenon cultural divergence.

We now verify to what extent the two results we obtained, cultural divergence and disappearance of one of the two cultures in the long run, are driven by the small open economy assumption, or whether they also obtain in a symmetric two-country general equilibrium framework.

\footnotetext{
${ }^{7}$ In our model, an upward sloping long run demand curve for factors of production is obtained through a demand side mechanism: this is due to endogenously biased preferences. Acemoglu (2002) shows that the same finding can originate from a supply side mechanism: this happens in presence of endogenously biased technical change.
} 


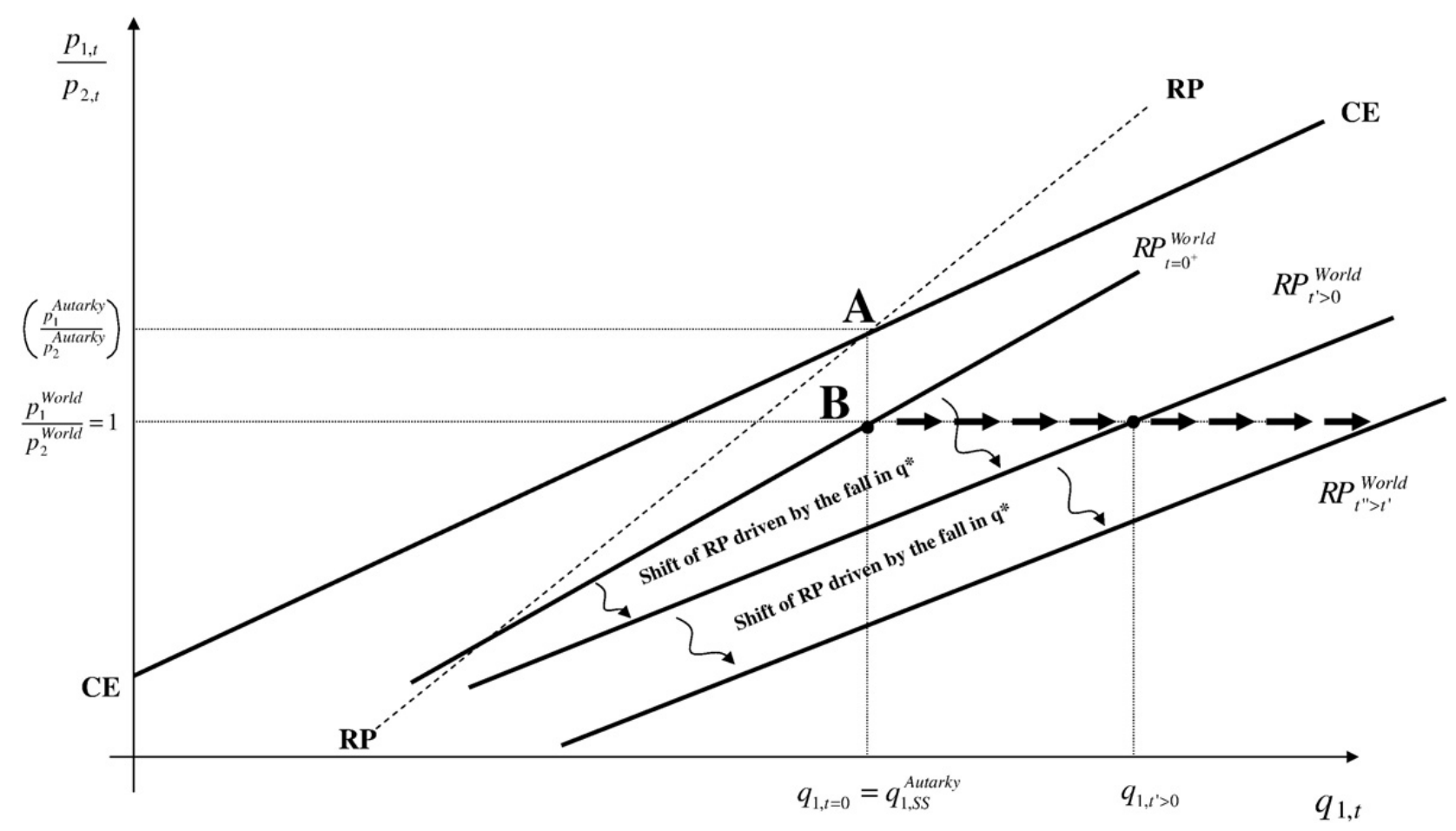

Fig. 4. Trade integration in a two-country economy.

\subsection{Trade integration in a two-country economy}

For ease of exposition, we now consider the polar case to the small open economy scenario, namely the case of two completely symmetric countries. More specifically, we assume:

$$
\begin{aligned}
& K_{1}=K_{2}^{*}=\kappa \in(1 / 2,1) \\
& K_{1}^{*}=K_{2}=1-\kappa \\
& \mathrm{SE}_{1}=\mathrm{SE}_{2} \equiv \mathrm{SE} .
\end{aligned}
$$

Where the * superscript refers to the foreign country. Fig. 4 depicts the equilibria under autarky and trade integration. Under autarky we get the RP curve for the home country:

$$
\left(\frac{p_{1, t}}{p_{2}, t}\right)=\left(\frac{1-\kappa}{\kappa}\right)^{\beta}\left(\frac{q_{1, t}}{1-q_{1, t}}\right)^{\beta} \text {. }
$$

And its equivalent for the foreign country:

$$
\left(\frac{p_{1, t}^{*}}{p_{2, t}^{*}}\right)=\left(\frac{\kappa}{1-\kappa}\right)^{\beta}\left(\frac{q_{1, t}^{*}}{1-q_{1, t}^{*}}\right)^{\beta}
$$

The CE curve is unchanged and given by:

$$
\frac{1+I_{1}\left(q_{1, t}\right)}{1+I_{2}\left(1-q_{1, t}\right)}=\frac{p_{1, t}}{p_{2, t}}
$$

Since $\kappa$ is larger than $1 / 2$, we get that:

$$
q_{1, S S}^{* \text { Autarky }}<q_{1, S S}^{\text {Autarky }} .
$$

Furthermore, given the symmetry of the problem, one necessarily have $q_{1, \mathrm{SS}}^{\text {Autarky }}=q_{2, \mathrm{SS}}^{* \text { Autarky }}$ and therefore

$$
q_{1, \mathrm{SS}}^{\text {Autarky }}+q_{1, \mathrm{SS}}^{* \text { Autarky }}=1 .
$$


Noting that at $q=1 / 2$ the CE curve takes a value of $p_{1} / p_{2}=1$, we obtain:

$$
\left(\frac{p_{1}^{*, \text { Autarky }}}{p_{2}^{*, \text { Autarky }}}\right)<1<\left(\frac{p_{1}^{\text {Autarky }}}{p_{2}^{\text {Autarky }}}\right) .
$$

Let us now consider full integration of the goods market. The CE curve is not affected while the RP curve now corresponds to international good markets clearing, (i.e. relative world demand equals to relative word supply). We show in the Appendix that the equilibrium relative world price is given by a function:

$$
\left(\frac{p_{1, t}^{\text {world }}}{p_{2, t}^{\text {world }}}\right)=\Psi_{w}\left(\frac{q_{1, t}+q_{1, t}^{*}}{2-\left(q_{1, t}+q_{1, t}^{*}\right)}\right) .
$$

with $\Psi_{w}($.$) increasing and such that \Psi_{w}(1)=1$.

Fig. 4 depicts then the impact of trade integration from the home country perspective. Using Eqs. (21) and (22), we find that just after trade integration the world relative price jumps to $p_{1, t=0^{+}}^{\text {world }} / p_{2, t=0^{+}}^{\text {world }}=\Psi_{w}(1)=1$, which is below the initial equilibrium relative price of the domestic economy. In other words, the RP curve shifts down to $\mathrm{RP}_{t=0^{+}}^{\text {world }}$. We observe that the CE curve is above $p_{1, t}^{\text {world }} /$ $p_{2, t}^{\text {world }}=1$ around $q_{1, \mathrm{SS}}^{\text {Autary }}$ and thus $q_{1, t}$ increases immediately after integration. The mechanism is symmetric for the foreign country and $q_{1, t}^{*}$ decreases after integration. From Eq. (22), we see that the decrease in $q_{1, t}^{*}$ lowers the world demand for good $X_{1}$ and pushes the RP curve further down, as depicted in Fig. 4. In fact, symmetry implies that, at all dates, $q_{1, t}=q_{2, t}^{*}$, or $q_{1, t}+q_{1, t}^{*}=1$, and thus the equilibrium international relative price $\left(\frac{p_{1, t}^{\text {world }}}{p_{2, t}^{\text {world }}}\right)$ remains constant and equal to 1 . It follows that $q_{1, t}$ keeps on increasing, and $q_{1, t}^{*}$ keeps on decreasing. As $q_{1, t}$ approaches 1 and $q_{1, t}^{*}$ approaches 0 , both the domestic and the foreign country enter pooling regimes, which amplifies the previous dynamics. Ultimately, trade integration causes complete cultural divergence and $q_{1, t} \rightarrow 1$ and $q_{1, t}^{*} \rightarrow 0$.

We conclude from this discussion that our earlier result that trade integration results in a dramatic change of the distribution of cultures across countries and in the (long-run) disappearance of one culture is not driven by the small open economy assumption. It obtains even in a perfectly symmetric 2-country general equilibrium model. The intuition is that prices in an integrated world depend only on world demand and not on local demands. If an increase of the local demand for one good is compensated by a decrease of the foreign demand for that good, world prices do not change.

Note that the initial trade shock amplifies autarkic cultural differences because: (i) the world price takes a value between the two autarkic prices and (ii) due to the presence of a home bias, a higher autarkic price corresponds to a larger $q_{1}$. Along the transition path, cultural evolution is driven by the same two opposite forces as under autarky: the externality effect and the relative price effect. Trade integration by reducing the sensitivity of goods' relative demand on local cultural characteristics dampens the relative price effect in the process of cultural evolution in each country. As the relative price effect is weaker, the cultural externality effect tends to dominate and leads to cultural homogeneity within country and cultural divergence across countries. ${ }^{8}$

The idea that trade integration causes cultural divergence is consistent with empirical evidence brought forward by Guiso et al. (2005). Guiso, Sapienza and Zingales look at the impact of trust on trade. A reasonable assumption to make is that how much agents of two countries trust one another as an increasing function of how close the cultures of the two countries are to one another. If we accept this interpretation, Guiso, Sapienza and Zingales find that the larger the cultural proximity between two countries, the more the two countries trade with one another. They also find that the coefficient of cultural proximity blows up significantly when cultural proximity is instrumented. The fact that the coefficient of cultural proximity in the regression with instrumental variables is significantly different from that in the OLS regression suggests that shocks to trade integration also have an impact on cultural proximity. The fact that the coefficient is strictly larger in the regression with instrumental variables than in OLS suggests that trade integration increases the cultural distance between countries, as our model predicts.

\section{Social integration}

Integration of goods markets is only one of many aspects of globalization. Revolutionary developments in information and transport technology lead to rising opportunities for social exchange with people living in far away regions or countries. We call social integration the fact that agents of different countries may meet and have social interactions with one another, be it through migration, student exchanges, internet chat rooms or tourism.

Our model allows us to model social integration in a very simple manner. Up to now, we assumed that social exchange was taking place only within the borders of each country. When deriving the exact form of the cultural externality in Section 2.2, we indeed postulated that the probability that an agent of culture $i$ is matched with an agent of the same culture is equal to the mass of agents of culture $i$ in the country, which leads to the expression for the cultural externality given by Eq. (4). We now refer to this situation as social autarky.

\footnotetext{
8 It can be shown that these cultural divergence dynamics are robust to a general supply side specific factor model of production for the economy. The details of the proof are available from the authors upon request or can be directly downloaded on http://www.unige.ch/ses/ecopo/staff/thoenig/thoenig.html.
} 


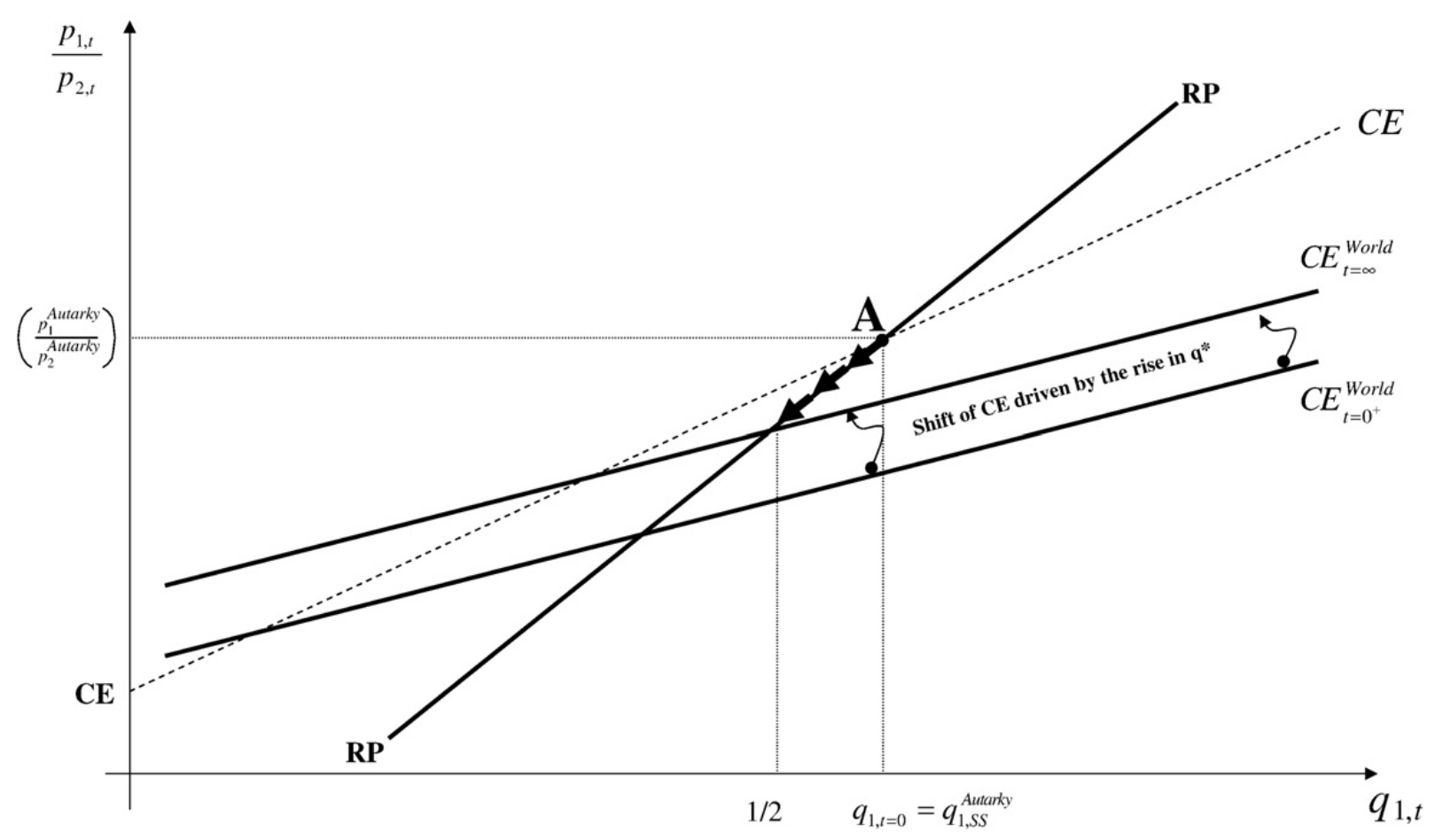

Fig. 5. Social integration in a two-country economy.

By way of contrast, we say that two countries are socially integrated if an agent of one of the countries may be matched with either an agent of her own country or with an agent of a different country with same probabilities. In that case social integration implies that the cultural externalities, which were formerly given by Eq. (4), now become:

$$
I_{i}^{\text {world }}\left(q_{i, t}+q_{i, t}^{*}\right) \equiv\left(1+\frac{q_{i, t}+q_{i, t}^{*}}{2}\left(\mathrm{SE}_{i}-1\right)\right)
$$

\subsection{Social Integration in a two-country economy}

For ease of exposition, we maintain the same assumption of completely symmetric countries as in Section 4.2. We assume that $X_{1}$ and $X_{2}$ are not traded but that the two countries are socially integrated. The dynamics after social integration in the home country are represented in Fig. 5. The RP curve is unchanged compared to autarky and is characterized by Eq. (17). However, the CE curve shifts now to the curve $\mathrm{CE}_{t-p^{+}}^{\text {world }}$ :

$$
\frac{p_{1, t}}{p_{2}, t}=\frac{2+(\mathrm{SE}-1)\left(\frac{q_{1, t}+q_{1, t}^{*}}{2}\right)}{2+(\mathrm{SE}-1)\left(1-\frac{q_{1, t}+q_{1, t}^{*}}{2}\right)}
$$

Given Eq. (20), there are initially more agents of culture 1 at home than abroad. Thus, the $C E^{\text {world }}$ curve is located to the right of $C E$ for $q_{1, t}$ close to $q_{1, \text { SS }}^{\text {Autary }}$ After social integration, good $X_{1}$ is too expensive compared to the externalities it provides. Thus $\dot{q}_{1, t}<0$ and the home economy moves down the RP curve. The opposite phenomenon arises in the foreign country and thus $\dot{q}_{1, t}^{*}>0$. As a consequence the $\mathrm{CE}^{\text {world }}$ curve shifts back upward. The economy reaches a steady-state when $q_{1, t}$ corresponds to the intercept of RP and $\mathrm{CE}_{t}{ }^{\text {world }}$. The symmetry assumption implies that the new long-run equilibrium is such that $q_{1}=q_{1}^{*}=1 / 2$.

We thus observe that social integration has the opposite impact from that of integration of goods markets: instead of causing cultural divergence, it causes cultural convergence across countries. The intuition for this result is that social integration provides a dilution of the cultural externalities. Whenever a culture is stronger in one country than in the rest of the world, it provides stronger externalities under social autarky than under social integration. This is because under social integration, agents get increasingly matched with agents from other countries where that culture is less prevalent. Thus, social integration tends to weaken the stronger cultures in all countries. This generates cultural heterogeneity within countries and cultural convergence across countries.

\subsection{Full integration in a two-country economy}

We have two forms of globalization with opposite effects on the cultural dynamics. A natural question to ask in our framework is the consequences of full integration, that is of both integration of goods markets and social integration occurring at the same time. 
We consider the same two symmetric countries as before and look at the impact of simultaneous trade and social integration. From the previous sections we get that the RP curve is now given by:

$$
\left(\frac{p_{1, t}^{\text {world }}}{p_{2, t}^{\text {world }}}\right)=\Psi_{w}\left(\frac{q_{1, t}+q_{1, t}^{*}}{2-\left(q_{1, t}+q_{1, t}^{*}\right)}\right) .
$$

While the CE curve becomes:

$$
\frac{p_{1, t}}{p_{2, t}}=\frac{2+(\mathrm{SE}-1)\left(\frac{q_{i, t}+q_{i, t}^{*}}{2}\right)}{2+(\mathrm{SE}-1)\left(1-\frac{q_{i, t}+q_{i, t}^{*}}{2}\right)} .
$$

As pointed out in Section 4.2, symmetry indeed implies that under autarky, we had: $q_{1, \text { Autarky }}=q_{2, \text { Autarky }}^{*}$, or $q_{1, \text { Autarky }}+q_{1, \text { Autarky }}^{*}=1$. It is straightforward to show that this observation implies that the distributions of cultures under autarky also constitute a long-run equilibrium under full integration! The relative price of the two goods jumps to its value 1 under full integration but cultures in both countries remain unchanged. The intuition is that the two effects of trade integration and social integration exactly counterbalance each other. On the one hand, a lower price for good $X_{1}$ increases the incentives of parents' culture 1 to socialize their children but on the other hand the dilution of cultural externalities due to increased interaction with agents of the foreign country where culture 2 is stronger reduces those incentives.

In an extension available upon request, we consider the case of general production functions for the supply side of the economy and show that the basic intuitions of the simple symmetric model that we exposed here still hold. However, depending on which effect is most dampened by international integration (the cultural externality effect or the relative price effect), the process of cultural evolution under full integration may reduce or amplify initial cultural differences along the transition path.

\section{Conclusion}

In this paper, we built up a simple dynamic model of preferences' evolution to analyze the interactions between international integration and cultural identity dynamics. Following the recent view expressed by Akerlof and Kranton (2000), we departed from the standard economic assumption that consumption occurs in a social vacuum. On the contrary, we adopted the position that goods generate social and cultural value in addition to their intrinsic consumption value, providing individuals with a sense of belonging to a particular community of people who share the same specificities. We integrated this dimension in a simple model of cultural transmission and international trade. We identified two opposite effects on cultural dynamics: an externality size effect leading to corner solutions and homogeneity within the population and a relative price effect pushing towards interior solutions and cultural diversity. Through this lens, we investigated the impact of two facets of globalization: international trade and social integration. Our framework points to the differential impact of commodity trade and social integration on the dynamics of identity values. By reducing the impact of local demand characteristics on relative prices, goods market integration tends to favor intercountry cultural divergence and within country homogeneity. On the opposite, by diluting local group externality effects, social integration creates global cultural dynamics convergence. While we hope our approach provides some interesting insights on the question of globalization and culture, it obviously does not touch a important number of dimensions.

For instance, we did not consider the other two facets of globalization, namely migration and foreign direct investment. As described by many historical accounts, migration has always been an important contributor to social interactions and cultural evolution. Immigrants assimilate with local host cultures while at the same time bringing elements of their native culture. The process of multinationalization and foreign direct investment is another dimension which is clearly at the heart of cultural industries. Allowing for such a channel should bring new insights on how global market forces affect local and global cultural trends.

More importantly, we have not discussed any normative perspective on trade and culture. It is obviously very difficult to make non-ambiguous normative statements when preferences are endogenous. Now, one very first step to move in this direction is to evaluate the impact of globalization from the perspective of each type of agent already born before trade integration occurred: if the relative price effects are not too strong and are dominated by the cultural externality effects, ${ }^{9}$ then the two groups of individuals could have opposite views on the benefits of trade integration. This kind of situation may then explain why cultural sectors are the battlefield of intense policy debates and opposition between and within countries.

\footnotetext{
${ }^{9}$ Consider for instance the case of the small open economy as described in Section 4.1 where commodity trade leads to the disappearance of cultural identity of type 1 . In autarky, a typical agent of type 1 would evaluate her welfare by $I_{1}\left(q_{1, \text { Autarky }}\right) / p_{1}^{\text {Autarky }}$. Now, consider for simplicity the steady state situation after trade integration. The same agent now has a level of welfare given by $1 / p_{2}^{\text {world }}$. According to this evaluation criterion, she feels worse off when $I_{1}\left(q_{1}\right.$, Autarky $) / p_{1}^{\text {Autarky }}>1 /$ $p_{2}^{\text {world }}$, that is when the cultural identity externality loss is larger than the relative price effect $p_{1}^{\text {Autarky }} / p_{2}^{\text {world }}$ that trade integration brings through a shift of consumption pattern from good 1 in autarky to good 2 under free trade. By the same reasoning, a type 2 individual feels better off when the cultural identity externality gain $I_{2}(1) / I_{2}\left(q_{2, \text { Autarky }}\right)$ is larger than the price effect $p_{2}^{\text {world }} / p_{2}^{\text {Autarky }}$.
} 
Clearly enough, this simple discussion abstracts completely from a full subjective welfare evaluation of what happens during the transition process to the steady-state, nor does it touch the important political economy question of how these conflicting views about trade and culture would be resolved and compared from a welfare point of view. While this is obviously beyond the scope of the present paper, we hope that our framework is flexible enough to allow future research to investigate these issues.

\section{Appendix A}

\section{Cultural dynamics}

Transition probabilities $P_{i j, t}$ that a parent of type $i$ has a child adopting a preference of type $j$ are given by:

$$
\begin{aligned}
& P_{i, i, t}=\tau_{i, t}+\left(1-\tau_{i, t}\right) q_{i, t} \\
& P_{i, j \neq i, t}=\left(1-\tau_{i, t}\right)\left(1-q_{i, t}\right)
\end{aligned}
$$

where $\tau_{i, t}$ denotes the endogenous probability that a parent of type $i$ socializes directly her own child. For instance, a child with a parent of type $i$ can acquire the social preference of type $i$ in two ways. With probability $\tau_{i, t}$ she may be directly socialized by her parent. Otherwise she remains naive and gets socialized by another old generation individual of type $i$ by random matching with probability $\left(1-\tau_{i, t}\right) q_{i, t}$. Given the transition probabilities, the fraction $q_{i, t+\mathrm{d} t}$ of individuals of type $i$ is given by:

$$
q_{i, t+\mathrm{d} t}=q_{i, t}(1-\lambda d t)+\lambda \mathrm{d} t q_{i, t} P_{i, i, t}+\lambda \mathrm{d} t\left(1-q_{i, t}\right) P_{j, i, t}
$$

which after substitution and the continuous time limit $\mathrm{d} t \rightarrow 0$ gives:

$$
\dot{q}_{i, t}=\lambda q_{i, t}\left(1-q_{i, t}\right)\left[\tau_{i, t}-\tau_{j, t}\right]
$$

In our approach, $\tau_{i, t}$ is the result of rational socialization choices by parents. This choice is costly and we assume that a parent faces a cost of socialization $H\left(\tau, q_{i, t}\right)$ which is increasing convex in the socialization effort $\tau$ and decreasing in the second argument. This second property is intended to capture the fact that there are positive cost externalities of socialization across individuals of the same cultural trait. ${ }^{10}$ Formally, each parent chooses $\tau_{i, t}$ to maximize

$$
u_{i}\left(q_{i, t}\right)+\gamma\left[P_{i, i, t} V_{i, i}+P_{i, j, t} V_{i, j}\right]-H\left(\tau_{i, t}, q_{i, t}\right)
$$

where $u_{i}\left(q_{i, t}\right)$ denotes the parent's indirect utility and $\gamma$ is the degree of altruism with respect to kids.

In our present context (see Bisin and Verdier, 2000 for a general analysis), we take the following simple parametrization for the cost of socialization function: $H(\tau, q)=\Psi(\tau)(1-q)$ with $\Psi($.$) increasing convex and \Psi(0)=\Psi^{\prime}(0)=0, \Psi^{\prime}(1)=+\infty$. The solution of Eq. (27) gives

$$
\tau_{i, t}=\Psi^{\prime-1}\left[\gamma\left(V_{i i, t}-V_{i j, t}\right)\right]=\Psi^{\prime-1}\left[\gamma \Delta V_{i, t}\right]
$$

and the dynamics of preferences are given by:

$$
\dot{q}_{i, t}=\lambda q_{i, t}\left(1-q_{i, t}\right)\left[\Psi^{\prime-1}\left(\gamma \Delta V_{i, t}\right)-\Psi^{\prime-1}\left(\gamma \Delta V_{j, t}\right)\right]
$$

\section{Autarkic equilibrium}

Lemma 1. Suppose $\mathrm{SE}_{i}<1+\frac{4 \beta}{(1-\beta)^{2}}$, then there exists $0<\underline{q}<\bar{q}<1$ such that: $\frac{1}{I_{2}\left(1-q_{1, t}\right)}<\frac{p_{1}}{p_{2}}\left(q_{1, t}\right)<I_{1}\left(q_{1, t}\right) \Leftrightarrow q 1, t \in(\underline{q}, \bar{q})$.

Proof. From Eq. (11), we have:

$$
\frac{p_{1}}{p_{2}}\left(q_{1, t}\right) I_{2}\left(1-q_{1, t}\right)=\left(\frac{K_{2}}{K_{1}}\right)^{\beta}\left(\frac{q_{1, t}}{1-q_{1, t}}\right)^{\beta}\left(1+\left(1-q_{1, t}\right)\left(\mathrm{SE}_{2}-1\right)\right) \equiv f\left(q_{1, t}\right)
$$

where $f(0)=0$ and $f(1)=+\infty$ and $f($.$) is continuous on [0,1]$.

\footnotetext{
10 This assumption neutralizes the "cultural substitutability effect" in Bisin and Verdier (2001) and thereby considerably simplifies the algebra.
} 
Hence

$$
\begin{gathered}
f^{\prime}\left(q_{1, t}\right)>0 \\
\Leftrightarrow \\
\frac{\beta}{\left(1-q_{1, t}\right)^{2}}\left(\frac{q_{1, t}}{1-q_{1, t}}\right)^{\beta-1}\left(1+\left(1-q_{1, t}\right)\left(\mathrm{SE}_{2}-1\right)\right)>\left(\mathrm{SE}_{2}-1\right)\left(\frac{q_{1, t}}{1-q_{1, t}}\right)^{\beta} \\
\Leftrightarrow\left(1+\left(1-q_{1, t}\right)\left(\mathrm{SE}_{2}-1\right)\right)>\left(\mathrm{SE}_{2}-1\right)\left(1-q_{1, t}\right) q_{1, t} \\
\Leftrightarrow \\
\beta+\left(\mathrm{SE}_{2}-1\right)\left(1-q_{1, t}\right)\left(\beta-q_{1, t}\right)>0
\end{gathered}
$$

The LHS of this equation being a polynomial of degree 2 , it is minimized for $q_{1, t}=\frac{1+\beta}{2}$ with a value equal to $\beta-\left(S E_{2}-1\right)\left(\frac{1-\beta}{2}\right)^{2}$. Under the condition $\mathrm{SE}_{i}<1+\frac{4 \beta}{(1-\beta)^{2}}$, this value is always positive. this means that $\forall q_{1, t}, f^{\prime}\left(q_{1, t}\right)>0$. As a consequence there exists $0<\underline{q}$ such that:

$$
\frac{1}{I_{2}\left(1-q_{1, t}\right)}<\frac{p_{1}}{p_{2}}\left(q_{1, t}\right) \Leftrightarrow q_{1, t}>\underline{q} .
$$

The proof of the second part of Lemma 1 follows the same route.

Lemma 2. Suppose $2\left(\mathrm{SE}_{1}-1\right)+2\left(\mathrm{SE}_{2}-1\right)+\left(\mathrm{SE}_{1}-1\right)\left(\mathrm{SE}_{2}-1\right)<16 \beta$ then there exists a unique solution to:

$$
\frac{2+\left(\mathrm{SE}_{1}-1\right) q_{1, t}}{2+\left(\mathrm{SE}_{2}-1\right)\left(1-q_{1, t}\right)}=\left(\frac{K_{2}}{K_{1}}\right)^{\beta}\left(\frac{q_{1, t}}{1-q_{1, t}}\right)^{\beta}
$$

Proof. Let set

$$
g(q) \equiv\left(\frac{q}{1-q}\right)^{\beta} \frac{2+\left(\mathrm{SE}_{2}-1\right)(1-q)}{2+\left(\mathrm{SE}_{1}-1\right) q}
$$

$g(0)=0$ and $g(1)=+\infty$ and $g($.$) is continuous on [0,1]$. If $g($.$) is also strictly increasing, there exists a unique solution to the equation$ above.

Straightforward computations give:

$$
g^{\prime}(q)>0 \Leftrightarrow\left\{\begin{array}{c}
4 \beta+2\left(\mathrm{SE}_{1}-1\right)(\beta-(1-q)) q+2\left(\mathrm{SE}_{2}-1\right)(\beta-q)(1-q) \\
+\left(\mathrm{SE}_{1}-1\right)\left(\mathrm{SE}_{2}-1\right)(1-q)(\beta-1) q>0
\end{array}\right.
$$

Let us call $h$ the LHS of the above inequality. Given that $\beta$ is positive, we know that:

$$
h>4 \beta-q(1-q)\left[2\left(S E_{1}-1\right)+2\left(S E_{2}-1\right)+\left(S E_{1}-1\right)\left(S E_{2}-1\right)\right]
$$

Lemma 2 follows from the observation that $q(1-q)$ takes values no larger than $1 / 4$ on the [0,1] interval.

From Lemma 1, Lemma 2 and $g$ strictly increasing, it is simple to conclude that there exists a positive number $S>0$ such that:

There exists a positive number $S$ such that for that for $\mathrm{SE}_{i} \in[1,1+S]$, there exists a unique solution to Eq. (16), which corresponds to a unique stable interior steady-state.

\section{Dynamics under free trade}

Denoting the competitive supply functions of the two goods by:

$Q_{1}\left(p_{1, t}, p_{2, t}, K_{1}, K_{2}\right)$ and $Q_{2}\left(p_{1, t}, p_{2}, t, K_{1}, K_{2}\right)$ in the home country

$Q_{1}^{*}\left(p_{1, t}, p_{2, t}, K_{1}^{*}, K_{2}^{*}\right)$ and $Q_{2}^{*}\left(p_{1, t}, p_{2}, t, K_{1}^{*}, K_{2}^{*}\right)$ in the foreign country

we get that the world market equilibrium prices are characterized by the equality between relative world demands and relative world supplies:

$$
\frac{q_{1, t}+q_{1, t}^{*}}{\left(1-q_{1, t}\right)+\left(1-q_{1, t}^{*}\right)} \frac{\left.p_{2, t}\right)}{p_{1, t}}=\frac{Q_{1}\left(p_{1, t}, p_{2, t}, K_{1}, K_{2}\right)+Q_{1}^{*}\left(p_{1, t}, p_{2, t}, K_{1}^{*}, K_{2}^{*}\right)}{Q_{2}\left(p_{1, t}, p_{2, t}, K_{1}, K_{2}\right)+Q_{2}^{*}\left(p_{1, t}, p_{2, t}, K_{1}^{*}, K_{2}^{*}\right)}
$$


Given the homogeneity of degree 0 of the competitive supply functions this can be rewritten as:

$$
\frac{q_{1, t}+q_{1, t}^{*}}{2-\left(q_{1, t}+q_{1, t}^{*}\right)}=\frac{p_{1, t}}{p_{2, t}} \frac{Q_{1}\left(\frac{p_{1, t}}{p_{2, t}}, 1, \kappa, 1-\kappa\right)+Q_{1}^{*}\left(\frac{p_{1, t}}{p_{2, t}}, 1,1-\kappa, \kappa\right)}{Q_{2}\left(\frac{p_{1, t}}{p_{2, t}}, 1, \kappa, 1-\kappa\right)+Q_{2}^{*}\left(\frac{p_{1, t}}{p_{2, t}}, 1,1-\kappa, \kappa\right)}
$$

where we also used the fact that

$$
K_{1}=K_{2}^{*}=\kappa \in(1 / 2,1) \text { and } K_{1}^{*}=K_{2}=1-\kappa .
$$

Given that the functions $Q_{1}\left(\frac{p_{1 . t}}{p_{2 . t}}, 1, \kappa, 1-\kappa\right)$ and $Q_{1}^{*}\left(\frac{p_{1, t}}{p_{2, t}}, 1, \kappa, 1-\kappa\right)$ are increasing in $\frac{p_{1 . t}}{p_{2 . t}}$ and that $Q_{2}\left(\frac{p_{1 . t}}{p_{2 t}}, 1, \kappa, 1-\kappa\right)$ and $Q_{2}^{*}\left(\frac{p_{1, t}}{p_{2, t}}, 1,1-\kappa, \kappa\right)$ are decreasing in $\frac{p_{1, t},}{p_{2, t}}$ it follows that the right hand side of Eq. (29) is an increasing function $\Theta\left(\frac{p_{1, t}}{p_{2, t}}\right)$ such that $\Theta(0)=0$ and $\Theta(+\infty)=+\infty$. Hence there is a unique world relative price solving Eq. (29) and given by

$$
\left(\frac{p_{1, t}^{\text {world }}}{p_{2, t}^{\text {world }}}\right)=\Psi_{w}\left(\frac{q_{1, t}+q_{1, t}^{*}}{2-\left(q_{1, t}+q_{1, t}^{*}\right)}\right)
$$

with $\Psi_{w}()=.\Theta^{-1}($.$) which is therefore also an increasing function.$

Now our symmetry assumption between the two countries implies :

$$
\begin{aligned}
& Q_{1}\left(\frac{p_{1, t}}{p_{2, t}}, 1, \kappa, 1-\kappa\right)=Q_{2}^{*}\left(1, \frac{p_{1, t}}{p_{2, t}}, 1-\kappa, \kappa\right) \\
& Q_{2}\left(\frac{p_{1, t}}{p_{2, t}}, 1, \kappa, 1-\kappa\right)=Q_{1}^{*}\left(1, \frac{p_{1, t}}{p_{2, t}}, 1-\kappa, \kappa\right)
\end{aligned}
$$

and thus

$$
\begin{aligned}
& Q_{1}(1,1, \kappa, 1-\kappa)=Q_{2}^{*}(1,1,1-\kappa, \kappa) \\
& Q_{2}(1,1, \kappa, 1-\kappa)=Q_{1}^{*}(1,1,1-\kappa, \kappa)
\end{aligned}
$$

and thus $\Theta(1)=1$ or $\Psi_{w}(1)=1$.

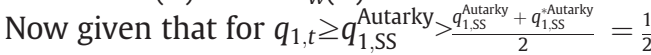

$$
\frac{2+(\mathrm{SE}-1) q_{1, t}}{2+(\mathrm{SE}-1)\left(1-q_{1, t}\right)}>1=\left(\frac{p_{1, t}^{\text {world }}}{p_{2, t}^{\text {world }}}\right) \text {. }
$$

It follows from Eq. (15) that for all $q_{1, t} \geq q_{1, S S}^{\text {Autarky }}, \dot{q}_{1, t}>0$ and thus that finally $q_{1, t} \rightarrow 1$. A symmetric argument provides that $q_{1, t}^{*} \rightarrow 0$ and there is cultural divergence between symmetric countries.

\section{Appendix B. Supplementary data}

Supplementary data associated with this article can be found, in the online version, at doi:10.1016/j.jinteco.2008.06.009.

\section{References}

Acemoglu, D., 2002. Directed technical change. Review of Economic Studies 69, 781-809.

Akerlof, G., Kranton, R., 2000. Economics and identity. Quarterly Journal of Economics 115, 715-753.

Bala, V., Van Long, N., 2005. International trade and cultural diversity: a model of preference selection. European Journal of Political Economy 21, 143-162.

Bisin, A., Verdier, T., 2000. Beyond the melting pot: cultural transmission, marriage and the evolution of ethnic and religious traits. Quarterly Journal of Economics $115,955-988$.

Bisin, A., Verdier, T., 2001. The economics of cultural transmission and the dynamics of preferences. Journal of Economic Theory 97, $298-319$.

Boyd, R., Richerson, P., 1985. Culture and the Evolutionary Process. University of Chicago Press, Chicago.

Cavalli-Sforza, L., Feldman, M., 1981. Cultural Transmission and Evolution: A Quantitative Approach. Princeton University Press, Princeton NJ.

Disdier, A.-C., Head, K., Mayer, T., 2006. Exposure to foreign media and changes in cultural traits: evidence from naming patterns in France. CEPR DP 5674.

Francois, P., 2002. Social Capital and Economic Development. Routledge, New York.

Francois, P., Van Ypersele, T., 2001. On the protection of culture. Journal of International Economics 56, 359-369.

Gould, D., 1994. Immigrant links to the home country: empirical implications for the US bilateral trade flows. Review of Economics and Statistics 61, 302-316.

Guiso, L., Sapienza, P., Zingales, L., 2005. Cultural Biases in Economic Exchange. CEPR DP 4837.

Janeba, E., 2004. International Trade and Cultural Identity. Mimeo University of Colorado.

Head, K., Ries, J., 1998. Immigration and trade creation: econometric evidence from Canada Canadian Journal of Economics 35, 47-62.

Mayda, A.M., Rodrik, D., 2005. Why are some people (and countries) more protectionist than others. European Economic Review 49, $1393-1691$.

Meunier, S., 2000. The French exception. Foreign Affairs 79, 104-116.

Ramezzana, P., 2003. Globalization and cultural diversity: the economics of the cultural exception. Mimeo University of Virginia.

Rauch, J., Trindade, V., 2006. Neckties in the tropics: a model of trade and cultural diversity. Mimeo University of California San Diego. 